\title{
Relaciones frías en la guerra fría: Hungría y Nicaragua
}

\section{Cold Relations in the Cold War: Hungary and Nicaragua}

\author{
Mónika Szente-Varga \\ (D) https://orcid.org/0000-0001-7403-6960 \\ Departamento de Relaciones Internacionales y Diplomacia \\ Facultad de Gobernanza Pública y Estudios Internacionales \\ Universidad Nacional de Servicio Público \\ (Nemzeti Közszolgálati Egyetem), Budapest, Hungría. \\ szente-varga.monika@uni-nke.hu
}

Resumen: Con base en los documentos resguardados en el Archivo Nacional de Hungría, el ensayo examina los aspectos políticos y económicos de las relaciones húngaro-nicaragüenses entre 1979 y 1990, dentro del marco de la guerra fría. Para la Unión Soviética, la importancia de América Latina se derivaba de su cercanía a Estados Unidos, contando así con una relevancia geoestratégica y política. En cambio, el principal atractivo de la región para Hungría fue el aspecto comercial. Hubo por tanto discrepancias entre las metas soviéticas y las húngaras. Naturalmente, Hungría se ajustó a las demandas de Moscú, pero tratando de sacrificar lo menos posible sus intereses nacionales. Esto contribuyó a crear una gran diferencia entre las expectativas nicaragüenses y la disposición húngara en la práctica. Si bien el ensayo subraya el rápido e indudable desarrollo de los contactos bilaterales, intenta al mismo tiempo eliminar el mito de las relaciones perfectas.

Palabras clave: guerra fría; política exterior; relaciones solidarias; Hungría; Nicaragua.

Cómo citAR: Szente-Varga, M. (2020). Relaciones frías en la guerra fría: Hungría y Nicaragua. Secuencia (108), e1808. DOI: https://doi.org/10.18234/secuencia.v0i108.1808

(c) 9

Esta obra está protegida bajo una Licencia Creative Commons Atribución-NoComercial 4.0 Internacional. 
Abstract: This essay analyses, within the framework of the cold war, the political and economic aspects of Hungarian-Nicaraguan relations in the period 1979-1990, based on documents of the Hungarian National Archive. The importance of Latin America derived from its proximity to the United States, having thus a geostrategic and political relevance for the Soviet Union. The principal attraction of the region for Hungary, on the other hand, was the commercial aspect, that of a potential market. There existed discrepancies between the Soviet and the Hungarian objectives. Naturally, Hungary adjusted to the demands of Moscow but tried to sacrifice as little as possible of its own national interests. This contributed to the formation of an abyss between the Nicaraguan expectations for solidarity and the Hungarian performance. Although this essay underlines the spectacular development of bilateral links, which undoubtedly took place, it tries to dissipate the myth of perfect relations.

Keywords: cold war; foreign policy; relations of solidarity; Hungary; Nicaragua.

Recibido: 24 de enero de 2020 Aceptado: 18 de mayo de 2020 Publicado: 22 de diciembre de 2020

$\mathrm{E}$ n mayo de 1956 el consejero de la embajada soviética en Budapest comentó a István Sebes, funcionario del Ministerio de Relaciones Exteriores, que en Moscú no estaban satisfechos con el nivel de las relaciones que la Unión Soviética tenía con los países latinoamericanos y los del Medio Oriente. Sabían, sin embargo, que Hungría había mantenido muy buenos nexos con estos estados en el pasado. En tal virtud, sugería que era conveniente, tanto para Hungría como para todo el bloque socialista, que Budapest revitalizara dichos contactos. La respuesta húngara fue positiva, naturalmente. De hecho, Sebes contestó que el Ministerio de Relaciones Exteriores de Hungría consideraba lo dicho como su tarea más inmediata (Baráth y Gecsényi, 2015, p. 39). Para terminar la historia, cabe añadir que, debido a la revolución húngara de 1956, esta promesa no se pudo cumplir. Fue hasta años después, a partir de principios de la década de 1960, que el gobierno húngaro comenzó a diversificar y extender sus lazos internacionales.

No obstante, el diálogo de arriba nos revela unos aspectos fundamentales de la política exterior húngara de la época de la guerra fría. Primero que nada, no podemos hablar de una política exterior independiente, represen- 
tando los intereses nacionales, puesto que existió una marcada dependencia de la Unión Soviética (URSS), y la postura de Hungría fue de un ajuste constante ante las demandas soviéticas. Por tanto, podemos utilizar el concepto de "interés nacional necesariamente restringido" (Békés, 2011, p. 65), que en la era Kádár ${ }^{1}$ significó que la política exterior tuvo que apoyar el desempeño económico y la política interior del país, con el fin de mantener la estabilidad interna.

América Latina no se consideró una prioridad. Su importancia fue más bien comercial, se le vio como un potencial mercado y fuente de divisas. Este concepto, sin embargo, no pudo ser aplicado en los casos de Cuba -primero-y Nicaragua, años después.

El presente ensayo analiza las relaciones entre Hungría y Nicaragua desde la victoria de los sandinistas en 1979, hasta la caída del bloque socialista en 1990, con un énfasis sobre el intercambio comercial y el apoyo húngaro (línea de crédito, ayuda económica y militar). Se basa principalmente en documentos del Ministerio de Relaciones Exteriores húngaro (Külügyminisztérium, en adelante KÜM), resguardados en el archivo nacional (Magyar Nemzeti Levéltár, Országos Levéltára, en adelante MNL OL). Estos abarcan textos acerca de los nexos húngaro-nicaragüenses, así como de la situación interna y las relaciones internacionales de Nicaragua, reunidos y, también -en muchos casos- elaborados por la embajada húngara en Managua, o por el Ministerio en Budapest. De esta manera proporcionan la perspectiva del gobierno de Hungría, y también el punto de vista de los representantes húngaros in situ, una mirada "fresca", de primera mano, que no necesariamente reflejaba la posición oficial húngara. Los documentos del archivo fueron complementados con la prensa de la época. Debido a las fuentes primarias, el análisis parte de una perspectiva húngara, pero los datos y procesos se presentarán en un contexto más amplio, incluyendo -en lo posible-comparaciones con la Unión Soviética y los demás países socialistas.

El análisis empieza con las políticas exteriores de la Unión Soviética y Hungría, y el papel de América Latina en ellas. Enseguida, y dentro del mismo contexto, estudiaremos los nexos húngaro-nicaragüenses en cuatro etapas cronológicas.

1 Época en que Hungría estuvo bajo el mando de János Kádár, que va desde la derrota de la Revolución de 1956 hasta finales de la década de 1980. Se divide en tres etapas cronológicas: represalias y consolidación (1956-1963), “dictablanda” (1963-1979) y decadencia (1979-1988/1989). 
En cuanto a los protagonistas, podríamos plantear las siguientes hipótesis: 1) Hubo discrepancias entre las metas soviéticas y húngaras. Naturalmente Hungría se ajustó a las demandas de Moscú, pero tratando de sacrificar lo menos posible sus intereses nacionales. Para decirlo de una manera simplificada y materialista: gastar poco. La ayuda húngara a Nicaragua, por consiguiente, no fue tan "voluntaria", ni tan generosa. Aunque se basó en parte en motivaciones internas de solidaridad, fue más bien resultado de factores político-ideológicos. 2) Existió una gran diferencia entre las expectativas nicaragüenses y el desempeño húngaro, causando fricciones entre los dos países. Dichas tensiones por lo general quedaron ocultas a los ojos del Oeste, y así las relaciones bilaterales parecieron ser excelentes. Por ser menos conocidos y estar poco investigados, este ensayo más bien se enfocará sobre estos problemas, pero hay que recalcar que todas estas interacciones se desarrollaron en el contexto de unos vínculos en crecimiento.

\section{IMPORTANCIA DE AMÉRICA LATINA}

\section{La relevancia de la región en la política exterior de la Unión Soviética}

Al principio de la guerra fría hubo una competencia de las dos superpotencias por Europa. Sin embargo, después de formarse la división, y con el paso de los años -ya para la segunda mitad de la década de 1950-, se hizo evidente que un cambio en el statu quo europeo podría resultar en una confrontación nuclear y, por tanto, en la aniquilación mutua. Consecuentemente, la rivalidad entre Estados Unidos y la Unión Soviética fue trasladada a otro espacio geográfico (Kanet, 2006, p. 331). La mayoría de los países en América Latina se habían independizado en la década de 1820, y 20 estados latinoamericanos fueron miembros fundadores de las Naciones Unidas en 1945. Tras la segunda guerra mundial el número de países creció en el mundo de una manera significativa, debido a los procesos de descolonización que tuvieron gran impacto en África, Asia y en el Caribe. El sistema internacional cambió de un bipolar rígido o estricto, a un bipolar flexible o relajado (Kaplan, 1957; Shearman, 1986, p. 339). Este último siguió siendo dominado por las dos superpotencias, pero aparte de ellas existía un gran número de otros países. Dichos estados pudieron servir como terrenos para una confrontación soviético-estadunidense, donde era posible llegar hasta conflictos calientes, aún durante la guerra fría. 
Desde principios de la década de 1950, con el declive de la "economía de guerra", hubo una necesidad en la Unión Soviética para abrirse hacia el mundo, sin embargo, el cambio verdadero en la política exterior de la URSS -y los países del bloque socialista- tuvo lugar después de la muerte de Stalin (Békés, 2011, p. 74) y se reforzó con el XX Congreso del Partido Comunista en 1956 y la consolidación de Kruschev en el poder. Este cambio y la naciente ambición de diversificar los contactos también se observa en la fundación de centros de investigación, como el Instituto de Economía Mundial y Relaciones Internacionales (1956), el Instituto de África (1960) y el Instituto de América Latina (1961), etc. (Shearman, 1986, p. 342). América Latina en sí no fue una prioridad para la Unión Soviética desde el punto de vista de su propia seguridad. Su valor se derivó del hecho de que era un área prioritaria para la seguridad de su rival, Estados Unidos.

Tanto los estadunidenses como los soviéticos tendieron a ver la guerra fría como un juego de suma cero, es decir, las ganancias soviéticas automáticamente se convertían en pérdidas estadunidenses, y viceversa (CIA, 1986, p. III; Kanet, 2006, p. 334; Mujan-Leon, 1986, p. 101). Tener una presencia soviética en América Latina, tan cerca de Estados Unidos, se podía traducir como una demostración de poder por parte de la Unión Soviética; un anuncio y confirmación de su estado de superpotencia; una mejora de su situación geoestratégica; una mueca burlona a Estados Unidos, y con ello la distracción de la otra superpotencia de áreas más significativas para la seguridad soviética (Desjeans y Clement, 1987, p. 223; Evanson, 1986, p. 79). Todo esto, y más, pudo haber tenido un rol en la decisión de Kruschev de apoyar espectacular (aunque no incondicionalmente) a la Cuba de Fidel Castro. Esta política arriesgada, dispendiosa y provocadora, que con toda certeza no caía muy lejos del carácter del líder soviético, llegó hasta la crisis de los misiles en 1962, llevando al mundo al margen de una guerra atómica. El retiro de los misiles y la derrota aparente de la Unión Soviética en la resolución del conflicto contribuyó en gran medida a la remoción de Kruschev dos años más tarde.

Desde la llegada al poder de Brézhnev ${ }^{2}$ hasta mediados de la década de 1970, la política exterior soviética fue más pragmática (Desjeans y Clement, 1987, pp. 224-225; Shearman, 1986, pp. 344-345), llegando a aceptar el statu quo existente en el mundo. Hubo más énfasis sobre los intercambios comerciales; las relaciones internacionales no necesariamente se limitaron a países socia-

${ }^{2}$ Líder soviético desde 1964 hasta su muerte en 1982. 
listas o de orientación socialista. ${ }^{3}$ Al mismo tiempo la Unión Soviética -y el bloque socialista- mantuvieron relaciones especiales con Cuba, pero no estuvieron dispuestos a repetir la práctica con otro país (Shearman, 1986, p. 339), por significar una merma sobre los recursos, así como por la experiencia no completamente satisfactoria obtenida en la isla (Bortlová Vondráková, 2011; Szente-Varga, 2005 y 2008).

Con las crisis petroleras de 1973 y 1979, el añoso liderazgo soviético llegó a la conclusión de que el mundo occidental estaba en problemas; por tanto, era la ocasión para el bloque socialista de avanzar e inclusive cambiar el statu quo a su favor. Consecuentemente abordaron una política exterior agresiva, incluyendo la invasión de Afganistán en 1979, que dio inicio a una etapa en la que las fricciones entre las dos superpotencias empeoraron, llamada la pequeña guerra fría (Fischer, 2014, pp. 289-315). La toma del poder por los sandinistas en Nicaragua ofreció la oportunidad a la Unión Soviética para fortalecer sus posiciones tanto en América Latina como en el mundo bipolar: "Los diplomáticos soviéticos recalcaron en las conversaciones que sostuvieron con nosotros, que la situación y el desarrollo en Nicaragua únicamente se pueden valorar y planear tomando en cuenta las interrelaciones políticas internacionales en un contexto global."

"La periferia imperial exterior" (Békés, 2012, p. 303) de la URSS -Cuba, Nicaragua, Angola, Etiopía, Zimbabue, etc.- ganó importancia en la pequeña guerra fría. Con el fin de mantener estos territorios en su órbita, la Unión Soviética, por una parte, gastó de sus propios recursos y, por la otra, requirió de la cooperación de los demás países socialistas.

\section{La relevancia de América Latina en la política exterior húngara}

Los lazos diplomáticos que fueron establecidos entre Hungría y los países latinoamericanos en el periodo de entreguerras quedaron rotos durante la segunda guerra mundial, y tras el conflicto hubo necesidad de remendarlos. Este proceso, sin embargo, resultó ser muy lento. En la segunda mitad de la década de 1940 únicamente se logró normalizar con Ecuador (1946) y con Ar-

\footnotetext{
${ }^{3}$ De hecho, estos últimos tendieron a ser los Estados menos desarrollados y más pobres (Light, 1991, p. 266).

${ }^{4}$ MNL OL, KÜM, j, 1979, IV, Nicaragua, caja 102/111-1/00984/12.
} 
gentina (1949). Después, con el desarrollo de la guerra fría, las posibilidades de restablecer las relaciones diplomáticas disminuyeron, puesto que los países latinoamericanos tendieron a no arriesgarse a afectar su armonía con Estados Unidos por tener vínculos con un país perteneciente al bloque socialista. En la década de 1950 los nexos húngaros en América Latina se diversificaron poco: Bolivia (1952) y Uruguay (1956). La revolución húngara de 1956 y la subsiguiente invasión soviética complicaron aún más la normalización de los contactos con América Latina. ${ }^{5}$ Los países latinoamericanos condenaron la intervención militar y se posicionaron en contra del gobierno Kádár, tomando una postura común en la "cuestión húngara" ante las Naciones Unidas hasta 1961.

Al final de 1960, el restablecimiento de las relaciones con Cuba trajo consigo un giro importante en la visión húngara; no solamente significó una creciente atención hacia la isla, sino que, a través de ella, hacia América Latina en general. En las décadas de 1960 y 1970 los nexos húngaros se multiplicaron en la región: Brasil (1961), Chile (1965), Perú y Venezuela (1969), Colombia (1973) y, tras más de tres décadas de distanciamiento, un país que siempre atrajo a la parte húngara, desde el principio: México (1974).

Para el gobierno húngaro América Latina por mucho tiempo significó América del Sur y México (aparte de Cuba, naturalmente). El istmo centroamericano empezó a aparecer en el radar húngaro desde 1970, cuando se normalizaron las relaciones diplomáticas entre Hungría y Costa Rica. Después siguieron Honduras (1973) y Panamá (1975). La conexión con la Nicaragua sandinista (1979) cuadró bien con el desarrollo de la política húngara hacia América Latina. ${ }^{6}$ Para esa fecha el país contaba con siete embajadas en la re-

${ }^{5}$ La revolución húngara de 1956 fue un movimiento armado en contra de las autoridades prosoviéticas, resultante de las tensiones derivadas del contraste entre los cambios internacionales que se venían dando (declaración de la neutralidad de Austria en 1955, críticas a Stalin en el XX Congreso del Partido Comunista de la URSS, y reformas políticas en Polonia en 1956), y la falta de cambios significativos en Hungría. Estalló el 23 de octubre de 1956, logrando una apertura en la vida política local, con la formación de varios partidos, y un gobierno de diferentes fuerzas políticas, bajo el liderazgo de Imre Nagy, un popular político comunista. Los objetivos incluían un sistema político democrático, la salida de las tropas soviéticas estacionadas en el país y la neutralidad de Hungría. Dichas metas sin embargo no se lograron, debido a la intervención militar soviética, iniciada el 4 de noviembre. Las consecuencias incluyeron la formación de un nuevo gobierno, bajo János Kádár; represalias; la emigración de unas 200000 personas, y la prolongada presencia de las tropas soviéticas en el país.

${ }_{6}^{6}$ Tras el golpe de 1973, Hungría rompió relaciones con Chile. Nuevos contactos fueron formados en el "Gran Caribe" en la segunda mitad de la década de 1970: Jamaica, Guyana, Trinidad y Tobago (1975), Granada y Surinam (1977) y, por último, Barbados (1978). 
gión y 19 relaciones diplomáticas (Magyar Külpolitikai Évkönyv, 1979, pp. 263277), lo que implica que en varios casos los países fueron cubiertos de una manera concurrente. Por ejemplo, la embajada húngara en la Ciudad de México cubría los países de América Central, y la oficina en Caracas los Estados del Caribe. El Ministerio de Relaciones Exteriores planeaba una acreditación concurrente para el caso de Nicaragua, sin embargo, debido a presiones provenientes de la propia Nicaragua y del bloque socialista, Hungría se vio obligada a crear una embajada en Managua. Para ello, el Ministerio echó mano de una directiva de 1979 que precisaba que "los fondos para el desarrollo de las representaciones húngaras en el extranjero se deben cubrir en lo posible con la reasignación de los medios disponibles", ${ }^{7}$ y tomó la decisión de cerrar su oficina en Rangún, Birmania, para nivelar, aunque fuera parcialmente, los gastos de la apertura de la embajada en Managua. ${ }^{8}$

"Los intereses de política exterior de los países pequeños por naturaleza son prioritariamente de carácter económico" (Kádár, 1988, p. 110). La importancia de América Latina para la Hungría socialista se derivó del hecho de que en su gran mayoría la componían países no socialistas, donde Hungría podía intentar colocar productos de exportación, hacer negocio a base de principios capitalistas, y así obtener divisas. Desde este punto de vista, la Nicaragua sandinista ya no cuadraba bien con las metas magiares, puesto que, como se indica, el gobierno húngaro, más que gastar recursos, deseaba aprovechar sus contactos latinoamericanos para obtener ingresos: "La escasa población de Nicaragua, y por ende las limitaciones de su mercado, aunadas a la condición crítica de su economía, significa que no es, ni será en los años venideros, un mercado considerable para el comercio exterior húngaro. Por tanto, si tomamos en cuenta únicamente razones económicas, en nuestra opinión, el desarrollo de los nexos económicos no se justifica".

Entre las consideraciones financieras/comerciales y las políticas ganaron las últimas. Las expectativas soviéticas prevalecieron sobre los intereses húngaros. ${ }^{10}$

${ }^{7}$ MNL OL, KÜM, j, 1980, IV, Nicaragua, caja 108/111-13.

8 MNL OL, KÜM, j, 1980, IV, Nicaragua, caja 108/111-13/00241/1.

9 MNL OL, KÜM, k, 1981, IV, Nicaragua, caja 70/111-54.

10 Durante la época socialista, investigar la dependencia de Hungría de la Unión Soviética -o más ampliamente, de las dos superpotencias- y las consecuentes limitaciones de su política exterior, no hubiera resultado un tema recomendable. Fue a partir de principios del siglo xxI que este campo de estudio recibió impulso y se desarrolló, gracias en gran parte a las 


\section{RELACIONES HÚNGARO-NICARAGÜENSES}

A pesar de la impresionante cantidad de documentos guardados en el Archivo Nacional de Hungría sobre relaciones húngaro-nicaragüenses en la década de 1980, no resulta fácil hacer un resumen. Por una parte, la gran variedad de las actividades rebasa los marcos de un solo ensayo. Por otro lado, las cantidades de dinero que figuran en los textos se anotan en diferentes divisas, no necesariamente convertibles y comparables: forintos húngaros, rublos soviéticos y dólares estadunidenses. No obstante lo anterior, un punto que llama la atención es que la asistencia financiera húngara, en comparación con la de los demás países socialistas, fue más que modesta.

Los nexos se analizarán en cuatro fases cronológicas. Las primeras dos son etapas que Ruben Berrios (1985, p. 120) utilizó para describir las actividades soviéticas -y que son válidas en el caso húngaro también-, que he complementado con dos etapas posteriores. Así, empezaremos con el periodo de exploración (1979-1981), cuando se firmaron varios acuerdos bilaterales estableciendo las bases de la cooperación, y continuaremos con los años de creciente compromiso (1981-1983), etapa que se caracteriza por diferentes tipos de ayuda e interacción, más amplia y vigorosa. Fue sin embargo a mediados de la década cuando Hungría dio su máximo apoyo (1983-1987), seguido por un distanciamiento (1987-1990), que llegaría al traslado de su embajada en 1991, de la capital nicaragüense a San José, Costa Rica.

\footnotetext{
investigaciones de Csaba Békés (2004, 2011, 2012, 2014) y László Borhi (2001, 2004a, 2004b, 2004c, 2006, 2010). A partir de la primera mitad de la década de 1960 -al mismo tiempo que los centros de investigación sobre América Latina se formaron en Checoslovaquia, Polonia y la URSS-, los estudios latinoamericanos fueron iniciados en la Universidad de Szeged por Tibor Wittman, y más tarde continuados por su discípulo, Ádám Anderle. La actual es la tercera generación de latinoamericanistas activa en Hungría. Sus investigaciones multifacéticas incluyen historia moderna y contemporánea, estudios culturales, de diáspora y migraciones, literatura de viajes, etc. Hasta ahora la guerra fría no ha sido foco de análisis, con algunas excepciones, como las repercusiones de la revolución húngara de 1956 en el mundo hispano (Anderle, 2007; Fischer, Kozma y Lilón, 2006) y los nexos húngaro-cubanos (Horváth, 2018; Szente-Varga, 2016; Udvardi, 2015; Zalai, 2010).
} 


\section{Periodo de exploración (1979-1981)}

El comienzo de la ayuda financiera húngara a Nicaragua se remonta a 1979, cuando el Consejo Ministerial hizo la donación de un hospital de campaña equipado con 400 camas, con un valor aproximado de 20000000 de forintos. Llama la atención el razonamiento que figura en la documentación húngara: "La ayuda gubernamental está justificada primeramente por razones políticas: por las tendencias progresistas del nuevo gobierno [nicaragüense] y, con base en ello, sus expectativas y disposición de cooperación con los países socialistas, así como por la ayuda ya manifestada por parte de la Unión Soviética y los demás países socialistas." ${ }^{11}$

El liderazgo húngaro claramente se ajustó al comportamiento "esperable" de un país socialista, e hizo esto durante toda la década, pero con decreciente entusiasmo.

Fue en el mismo año de la donación del hospital, en 1979, cuando el 1 de octubre Hungría y Nicaragua establecieron relaciones diplomáticas, después de actos similares por parte de la República Democrática Alemana (RDA) y Cuba, ${ }^{12}$ pero antes que la Unión Soviética (18 de octubre de 1979). Se trata de una secuencia planeada, con el fin de que esta última no quedara tan conspicua en un área cercana a Estados Unidos, que formaba parte de la zona de seguridad de ese país. Hungría abrió su embajada en Managua en el verano de 1980. El gobierno nicaragüense también quiso contar con una representación en Budapest, pero sin incurrir en gastos. La parte húngara no estuvo muy entusiasmada ni tuvo una respuesta rápida a la petición. De hecho, el Ministerio de Relaciones Exteriores de Hungría pidió a sus misiones en Moscú, Berlín, Praga y Sofía mandar reportes sobre las condiciones que gozan las embajadas nicaragüenses en dichas ciudades. El objetivo era comparar y hacer una evaluación del nivel de ayuda que se debía ofrecer. ${ }^{13}$ La decisión, sin embargo, no se tomó sino hasta 1982.

Entre tanto, en 1980 fue firmado un acuerdo comercial bilateral y también otro de cooperación tecnológica y científica, que se implementaría a través de planes de trabajo anuales. Asimismo, fue enviada una contribución

\footnotetext{
11 MNL OL, KÜM, j, 1979, IV, Nicaragua, caja 102/111/ 004467/10.

12 MNL OL, KÜM, j, 1979, IV, Nicaragua, caja 102/111-1.

13 MNL OL, KÜM, k, 1982, IV, Nicaragua, caja 77/111-17.
} 
gubernamental por un valor de 5000000 de forintos, que constaba de medicamentos y comestibles, específicamente latas de carne, frijoles y aceite. ${ }^{14}$

En resumen, fue una época que podemos describir con el establecimiento de los marcos oficiales de la cooperación y el inicio de los envíos de asistencia. El comercio bilateral fue insignificante: las importaciones húngaras desde Nicaragua fueron inexistentes, mientras las exportaciones no llegaron a sobrepasar los 16000 dólares estadunidenses en 1979 y 180000 en $1980 .^{15}$ Existió un escepticismo por parte del gobierno húngaro, por los potenciales gastos que preveían en esta relación, así como respecto al carácter "verdaderamente socialista” de Nicaragua (Szente-Varga, 2018, pp. 80-82).

\section{Años de creciente compromiso (1981-1983)}

Finalmente, en febrero de 1982 el Ministerio hizo una propuesta al Buro Político para proveer fondos -calcularon alrededor de 10000000 de forintoscon el fin de establecer una embajada nicaragüense en la capital húngara y cubrir su funcionamiento desde su apertura en la segunda mitad de 1982, hasta $1984 .{ }^{16}$ En efecto, la representación abrió sus puertas en Budapest en 1982 y la primera embajadora fue Eva Conrado Flores.

Ese mismo año el gobierno húngaro otorgó a Nicaragua una línea de crédito de 5000000 de dólares estadunidenses, a través del Banco Nacional. ${ }^{17}$ Para evaluarla, hay que tomar en cuenta el crédito ofrecido por otros países. En la lista que recoge los préstamos y líneas de crédito para Nicaragua entre julio de 1979 y junio de 1984 (Berrios, 1985, p. 126), Hungría figura con los 5000000 de dólares ya mencionados. En el caso de los países socialistas, la cantidad más grande fue proporcionada por la Unión Soviética (262 200000 dólares), seguida por la RDA (140 000 000), Bulgaria (60 000000$)$, Cuba (53 400 000) -jdiez veces más que Hungría!-, Checoslovaquia (30 000 000)

${ }^{14}$ MNL OL, KÜM, k, 1981, IV, Nicaragua, caja 70/111-54.

15 MNL OL, KÜM, k, 1984, IV, Nicaragua, caja 85/111-51.

${ }^{16}$ MNL OL, KÜM, k, 1982, IV, Nicaragua, caja 77/111-17.

17 Fecha de vencimiento para productos de consumo: 1 año; para proyectos de infraestructura: 6 años con una posible prórroga de 18 meses. Tipo de interés: 7.25\%, de lo que el Banco Nacional de Hungría reembolsará 1.25\%. MNL OL, KÜM, k, 1984, IV, Nicaragua, caja 85/111-51. 
y Yugoslavia ${ }^{18}$ (25000 000) -aún cinco veces mayor que la línea de crédito húngara (véase gráfica 1 ).

Ampliando la perspectiva y analizando la participación socialista en relación con la ayuda en general, es de recalcar que, según la fuente, en el periodo estudiado (1979-1984) los países socialistas cubrieron únicamente $24.2 \%$ de los préstamos y líneas de crédito para Nicaragua, mientras América Latina -sin Cuba, que se contó en el primer grupo- proporcionó 30\%. El país más generoso fue México (519 000000 de dólares estadunidenses), seguido por Venezuela (64 200 000), Brasil (50 500 000) y Argentina (47 800 000). En conjunto, la línea de crédito húngara -que a primera vista puede parecer impresionante- no sobrepasó el 0.2\% del total (Berrios, 1985, p. 126). Después de la visita de Daniel Ortega a Hungría en 1985 -ya como presidente-, el gobierno húngaro accedió a ofrecer otra línea de crédito más, pero igualmente por 5000000 de dólares estadunidenses. ${ }^{19}$

Existen cuadros estadísticos sobre la asistencia prestada por Hungría entre 1981 y 1984. Las cantidades iban creciendo, pero es menester añadir que desde el principio se trató de montos muy bajos. Este apoyo, que incluía auxilio civil -organizado y distribuido por el Comité de Solidaridad y la Cruz Roja Húngara- así como cooperación tecnológica y científica, fue de 2700000 ¡de forintos! en 1981. Se triplicó para el año siguiente (8 900000 en 1982) y siguió creciendo: 24300000 en 1983, y 148200000 en 1984. ${ }^{20}$ A partir de 1983 figuró también la ayuda militar, que formó aproximadamente una tercera parte de todo el apoyo otorgado, tanto en 1983 como en 1984. Puesto que el total de 1984 fue seis veces más que en 1983, y la cooperación militar retenía su proporción relativa, llegamos a un crecimiento espectacular en este renglón, de 7800000 en 1983 a 43900000 en $1984^{21}$ (véase gráfica 2).

No se desprende claramente de los documentos archivísticos en qué consistió la ayuda militar. Se sabe, sin embargo, que cuando Jaime Wheelock, ministro de Agricultura, estuvo de visita en Hungría en diciembre de 1980, mantuvo conversaciones con el ministro de Defensa, Lajos Czinege, y con el

${ }^{18}$ No fue ni miembro fundador, ni miembro completo. Después de ser observador por unos años en la década de 1950, se unió a la organización en 1964 en calidad de participante limitado.

${ }^{19}$ MNL OL, KÜM, k, 1989, IV, Nicaragua, caja 89/111-1.

${ }^{20}$ MNL OL, KÜM, k, 1984, IV, Nicaragua, caja 85/111-51.

${ }^{21}$ MNL OL, KÜM, k, 1984, IV, Nicaragua, caja 85/111-51. 
Gráfica 1. Préstamos y líneas de crédito a Nicaragua, julio de 1979-junio de 1984 (en millones de US\$)

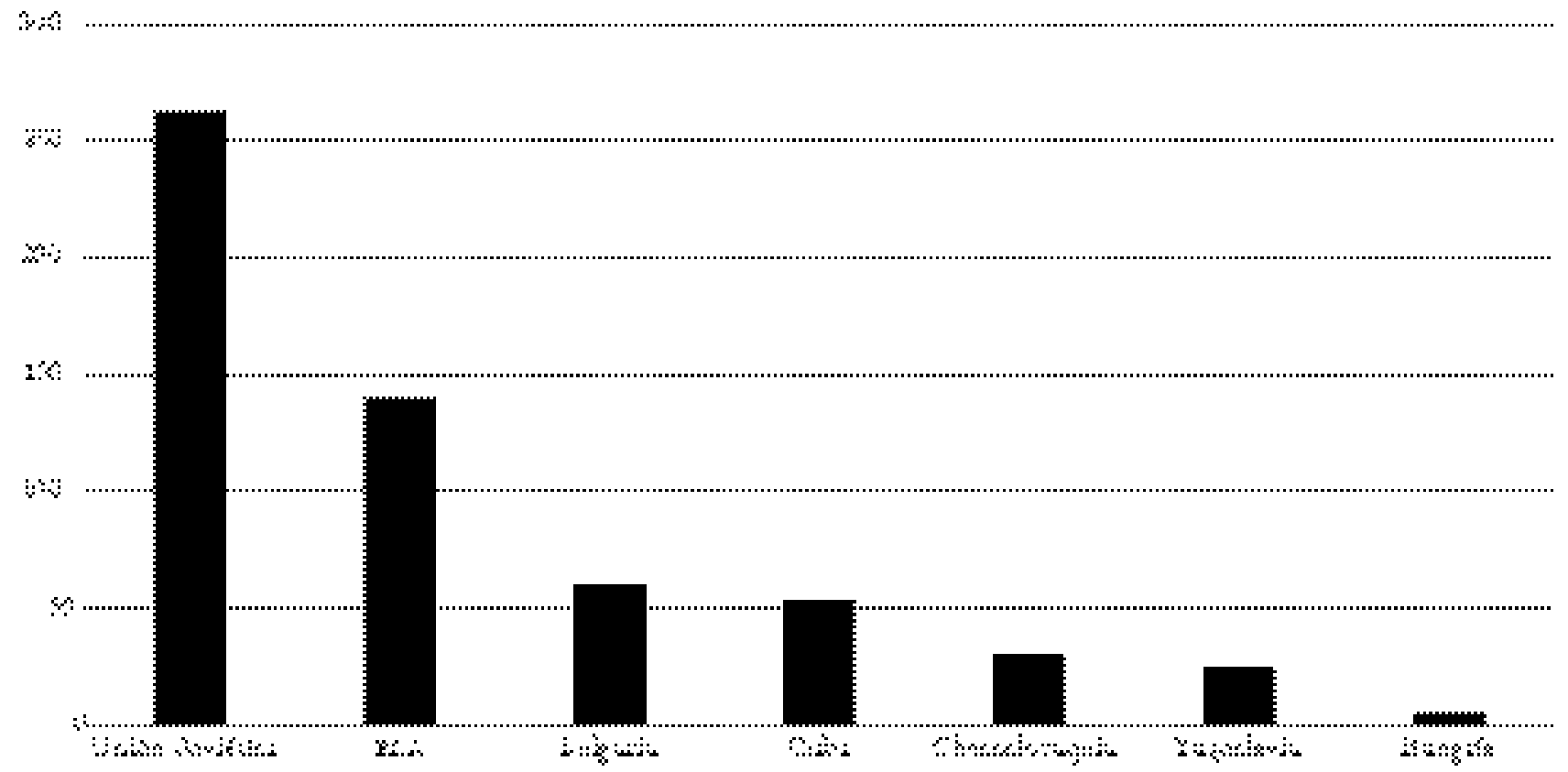

Fuente: Datos de Berrios (1985, p. 126). Elaboración propia. 
Gráfica 2. Auxilio húngaro prestado a Nicaragua entre 1981 y 1984 (en millones de forintos)

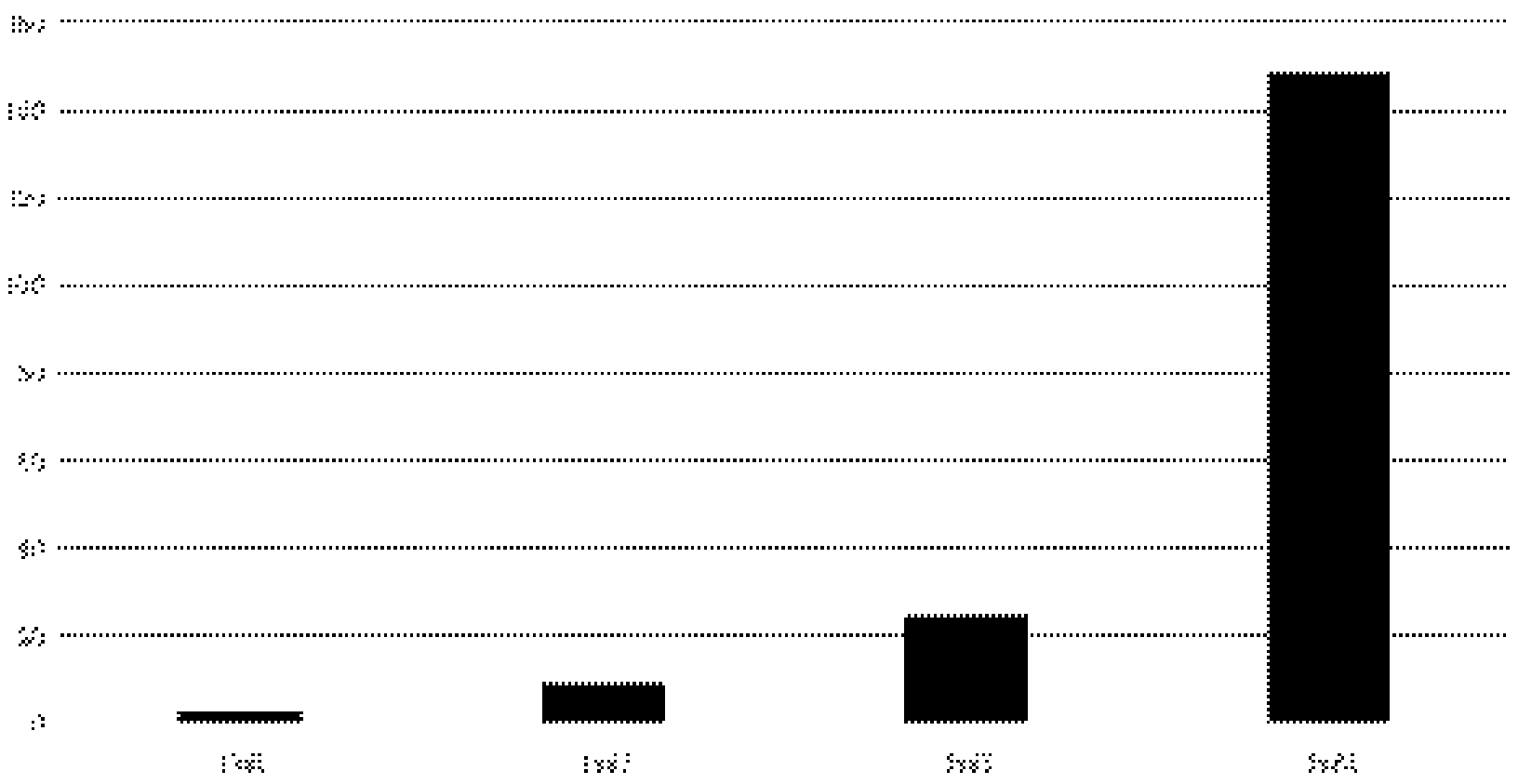

Fuente: Datos de MNL OL, KÜM, k, 1984, IV, Nicaragua, caja 85/111-51. Elaboración propia. 
líder de las milicias obreras, ${ }^{22}$ Sándor Borbély, sobre el equipamiento de algunas unidades de la milicia popular en Nicaragua. Según la documentación húngara, Czinege y Borbély apoyaron la petición, y en caso de una decisión política favorable por parte del gobierno húngaro, considerarían posible proveer con armas y equipo a tres batallones de milicianos nicaragüenses dentro de un tiempo corto. Calcularon los gastos en 11000000 de forintos. ${ }^{23}$ Hay otra alusión a cooperación militar en 1980. El 3 de enero el Departamento de Seguridad Personal del Ministerio del Interior de Nicaragua se dirigió al embajador Antal Sólyom en Managua, solicitando "25 pistolas para ordenanzas Modelo 1939 FromMER, de calibre 380 ACP 9 mm, Browning, o bien revólveres calibre 38 " ${ }^{24}$ La respuesta no fue negativa, si bien el jefe del Departamento de Relaciones Internacionales del Ministerio del Interior de Hungría indicó que "no contamos con las pistolas indicadas. Sin embargo, tenemos en nuestro sistema pistolas Makarov de $9 \mathrm{~mm}$, y si estas les convienen a los nicaragüenses podemos mandar 25 piezas. En caso de una respuesta afirmativa, una pregunta adicional es si necesitan municiones, y en qué cantidad." ${ }^{25}$ Otra alusión a la ayuda militar se conectó con la visita de Daniel Ortega en 1985, cuando hubo una pregunta por parte de Checoslovaquia sobre si Hungría estaba suministrando armas a Nicaragua. ${ }^{26}$ De todas maneras, aunque dicho respaldo militar incluyera una cierta cantidad de pistolas o rifles, posiblemente consistió más bien en equipo, como tiendas, pues los proveedores típicos de armas fueron la Unión Soviética y Checoslovaquia.

Hubo un crecimiento espectacular en las importaciones húngaras desde Nicaragua. Las cifras respectivas, 3133000 dólares en 1981; 3604000 en 1982, y 2288000 en 1983 pueden parecer poco, pero hay que tomar en cuenta que anteriormente esta interacción no había existido. ${ }^{27}$

En resumen, la apertura de la embajada de Nicaragua en Budapest con fondos húngaros, la línea de crédito de 5000000 de dólares, la compra de productos nicaragüenses, así como la ayuda sin retribución enviada por Hungría, manifiestan un creciente compromiso hacia el país centroamericano a principios de la década de 1980.

\footnotetext{
22 Organización paramilitar que funcionó entre 1956 y 1989.

${ }^{23}$ MNL OL, KÜM, j, 1980, IV, Nicaragua, caja 108/111-13/ 006252/4.

${ }^{24}$ MNL OL, KÜM, j, 1980, IV, Nicaragua, caja 108/111-99/001331.

25 MNL OL, KÜM, j, 1980, IV, Nicaragua, caja 108/111-65/0079/8.

${ }^{26}$ MNL OL, KÜM, j, 1985, IV, Nicaragua, caja 113/111/002223/19.

${ }^{27}$ MNL OL, KÜM, k, 1984, IV, Nicaragua, caja 85/111-51.
} 


\section{Época de máximo apoyo (1983-1987)}

1984 fue el año en que Hungría importó productos nicaragüenses por el valor más alto en la época, que ascendió a 5266000 dólares. Los números también fueron relativamente altos en 1985 (3 260 000) y en 1986 (2 231000 ) pero mostrando ya una tendencia decreciente. Los productos en cuestión fueron principalmente café, algodón, plátano y hierbas medicinales. Las exportaciones húngaras crecieron en comparación con el principio de la década, pero muestran una imagen confusa: 78000 dólares en 1981; 82000 en 1982; 722000 en 1983; 2859000 en 1984; 380000 en 1985 y 2015000 en 1986. El saldo comercial fue negativo para Hungría (véase cuadro 1).

La imagen -y los datos- desde el lado nicaragüense fueron sin embargo diferentes. Según las estadísticas del Ministerio de Economía, Industria y Comercio (MEIC), disponibles para 1986, las exportaciones a Hungría fueron inexistentes, y las importaciones no sobrepasaron los 1200 dólares, del total de 350865500 dólares por productos comprados a los países del Consejo de Ayuda Mutua Económica (CAME). ${ }^{28}$ Otros dos países con estadísticas similares, pero un poco más positivas que las de que Hungría, fueron Checoslovaquia y Polonia. En contraste, los países más activos incluyeron a la Unión Soviética, la RDA, Bulgaria y Cuba. En 1986, 61\% del comercio exterior de Nicaragua se desarrolló con países no socialistas, $24.2 \%$ con la Unión Soviética, y el resto con miembros del CAME. ${ }^{29}$

Continuemos con la perspectiva oficial húngara:

En el periodo de 1981 a 1987, nuestra patria proveyó a Nicaragua ayuda sin retribución con un valor total de aproximadamente 486 millones de forintos, principalmente en forma de medicamentos, utensilios médicos, víveres, ropa, productos especiales y de cooperación tecnológico-científica, etcétera. Aparte, suministramos 30,000 toneladas de petróleo en 1985, 50,000 toneladas en 1986 y 10,000 en 1987, igualmente como ayuda sin retribución, con un valor de 610 millones de forintos. Consecuentemente la cantidad total de apoyo sobrepasó

${ }^{28}$ MNL OL, KÜM, k, 1988, IV, Nicaragua, caja 73/111-5, cuadro 6.

${ }^{29}$ MNL OL, KÜM, k, 1988, IV, Nicaragua, caja 73/111-5, cuadro 4. Si tomamos el intercambio comercial de Nicaragua con los países del CAME como 100\%, la proporción de los diferentes países en 1986 fue como sigue: Unión Soviética, 61.9\%; Cuba, 14.2\%; RDA, 12.3\%; Bulgaria, 6.7\%; Checoslovaquia, 4.6\%; Polonia, 0.3\%; Hungría, 0\%. No figura Rumania. MNL OL, KÜM, k, 1989, IV, Nicaragua, caja 89/111-5. 


\section{Cuadro 1. Comercio de Hungría con Nicaragua, 1981-1987 (en miles de US\$)}

$\begin{array}{lrc}\text { Año } & \text { Exportaciones húngaras a Nicaragua } & \text { Importaciones húngaras desde Nicaragua } \\ 1981 & 78 & 3133 \\ 1982 & 82 & 3604 \\ 1983 & 722 & 2288 \\ 1984 & 2859 & 5266 \\ 1985 & 380 & 3260 \\ 1986 & 2015 & 2231 \\ 1987 & 898 & 48\end{array}$

Fuente: MNL OL, KÜM, k, 1989, IV, Nicaragua, caja 89/111-1.

los mil millones de forintos, lo que atestigua que Nicaragua fue el país que más auxilio recibió de Hungría entre los países de orientación socialista. ${ }^{30}$

Si restamos de la primera cantidad indicada (486 000000$)$ la ayuda enviada en 1981 y 1982 (11 600000 en total), tendríamos 474600000 de forintos para el periodo de 1983-1987, más de $97 \%$ del total.

Se nota un aumento en la asistencia a partir de 1983-1984, paralelamente con la reducción del apoyo por parte de los países no socialistas y el creciente aislamiento del gobierno sandinista. Las medidas estadunidenses punitivas -suspensión de la ayuda en mayo de 1981, seguida por la prohibición de todo el comercio con Nicaragua a partir de mayo de 1985-, de hecho, contribuyeron a la intensificación de los acercamientos entre Nicaragua y el lado socialista del mundo bipolar. "La situación actual [1985] del sistema sandinista es sumamente adversa”, opinó el embajador húngaro en Managua.

El destino de la revolución nicaragüense puede ser influenciado en gran medida por las condiciones internacionales, entre ellas el desarrollo del nexo soviético-estadounidense. Desempeña un papel principal la ayuda política y

30 MNL OL, KÜM, k, 1989, IV, Nicaragua, caja 89/111-5. 
económica de los países socialistas, de la cual depende no solamente la supervivencia de la revolución sino también su desarrollo o posible desviación. ${ }^{31}$

Los líderes nicaragüenses trataron de presionar a los países socialistas para obtener más ayuda. Se realizaron giras por el bloque. Daniel Ortega, por ejemplo, visitó Hungría dos veces, en 1984 y en 1985. Aprovechó también la 39 Reunión del cAme para pedir apoyo. Se había dirigido a los primeros secretarios de los partidos comunistas de los países miembros de la organización pidiendo urgente auxilio económico, petición que confirmó personalmente en el otoño de 1984 en la capital cubana, donde la reunión tuvo lugar. Las delegaciones soviética, búlgara y alemana oriental ofrecieron aumentar el suministro de créditos y de cooperación, mientras las delegaciones húngara, checoslovaca y polaca prometieron contestar dentro de un mes, tratando de esquivar nuevos gastos. ${ }^{32}$ No obstante, el ministro Henry Ruiz Hernández visitó dichos países para concretar la ayuda -estuvo en Budapest el 7 de diciembre de 1984- (Magyar Külpolitikai Évkönyv, 1984, p. 55).

A mediados de la década de 1980 fue el periodo cuando Hungría gastó más en Nicaragua debido a las expectativas soviéticas, pero no a sus propias condiciones económicas, puesto que estas iban empeorando. El crecimiento económico se redujo de 2.9\% (1976-1980) a 1.6\% (1981-1985) y Hungría quedó cada vez más endeudada. Mientras la limitación más importante de la política exterior húngara fue la influencia soviética, hay que añadir que Hungría también dependía del Oeste hasta cierto grado, sobre todo de los préstamos de los países occidentales, así como de su tecnología -y las divisas para obtenerla-. Los intereses domésticos húngaros chocaron con las obligaciones socialistas. Las recomendaciones para la posición húngara en cuanto a las negociaciones con Ruiz Hernández incluían por tanto las siguientes ideas: "Amén de expresar nuestra solidaridad, hay que mencionar el soporte que hemos brindado hasta ahora, y apuntar las limitaciones conectadas con nuestra situación económica." ${ }^{33}$ Esto naturalmente no se pudo hacer con toda franqueza, puesto que en la guerra fría las apariencias fueron muy importantes. El bloque socialista siempre pareció más fuerte de lo que realmente era, una imagen que le ganó admiradores y seguidores, y ayudó a controlar a sus riva-

\footnotetext{
31 MNL OL, KÜM, j, 1985, IV, Nicaragua, caja 113/111/004025.

32 MNL OL, KÜM, k, 1984, IV, Nicaragua, caja 85/111-51.

33 MNL OL, KÜM, k, 1984, IV, Nicaragua, caja 85/111-51.
} 
les. Al mismo tiempo esto también causó fricciones, ya que varios gobiernos, específicamente los de Cuba y Nicaragua, consideraron la cooperación insuficiente y no al nivel de las capacidades del bloque: "Sopesando criterios económicos, no se puede proponer la aceptación de las peticiones nicaragüenses. Nicaragua abiertamente admite que espera de los países del CAME en el marco de la solidaridad revolucionaria, apoyo sin retribución, y un trato más favorable que en el mercado mundial (preferencia de precio). Proyecta el reembolso de nuestra ayuda para la década de 1990". ${ }^{34}$

Hay una recurrente insistencia en los textos húngaros de que la asistencia se da por motivos políticos, lo que hace anticipar que esta situación dejaría de existir casi automáticamente una vez que desaparezcan las presiones ideológicas.

\section{Años de distanciamiento (1987-1990)}

El cambio de la política exterior soviética en cuanto a Nicaragua no se hizo inmediatamente con el ascenso de Mijaíl Gorbachov al poder, sino unos dos años más tarde. "Para poder cambiar su política en Nicaragua y en América Central, la Unión Soviética primero tuvo que cambiar su política hacia Washington. Junto con el cambio, también tuvo que revisar su perspectiva sobre los conflictos regionales en el tercer mundo" (Blank, 1993, p. 11). Durante la visita de Daniel Ortega a la Unión Soviética en noviembre de 1987, Gorbachov le advirtió sobre una potencial disminución del socorro soviético en el futuro (Vanden y Prevost, 1993, p. 105). Viendo el cambio de la actitud de la URSS como una luz verde para reducir obligaciones hacia Nicaragua, así como motivado por la crítica situación económica, el gobierno húngaro también quiso bajar los gastos en América Central. De hecho, Hungría dejó de crecer en la segunda mitad de la década de 1980 y tuvo un cambio en su producto interno bruto (РIB) a 0.3\% (1986-1990), convirtiéndose en el estado más endeudado entre los países socialistas en cuanto a valor de la deuda per cápita (Romsics, 1999, p. 454).

El cambio de actitud es palpable en el terreno del comercio bilateral. Las importaciones húngaras de Nicaragua cayeron en comparación con las cifras de la primera mitad de la década: 48000 dólares en 1987; 886000 en 1988

\footnotetext{
34 MNL OL, KÜM, k, 1984, IV, Nicaragua, caja 85/111-51.
} 
y 620000 en 1989. Al mismo tiempo se puede notar un intento de aumentar las exportaciones: 898000 dólares en 1987; 3343000 en 1988 y 591000 en $1989^{35}$ con el fin de conseguir un saldo positivo en el intercambio comercial. ${ }^{36} \mathrm{Las}$ exportaciones húngaras, sin embargo, tuvieron varias limitaciones, entre ellas la insolvencia del gobierno nicaragüense, la desconfianza del sector privado, el tamaño restringido del mercado de destino, la poca experiencia de las empresas húngaras para competir en América Latina, etc. Entre las dos partes, el gobierno húngaro fue el que se interesó en desarrollar contactos bilaterales de comercio, mientras que, debido a las condiciones que tuvieron que enfrentar, los líderes nicaragüenses prefirieron el auxilio unilateral proveniente de Hungría.

Las tensiones entre los líderes nicaragüenses y la parte húngara se manifestaron durante el IV Encuentro de la Comisión Mixta del came y Nicaragua, celebrado en 1987:

El presidente Daniel Ortega en la recepción ofrecida por los líderes de las delegaciones, así como el ministro de comercio exterior y cooperación Henry Ruiz, en la sesión plenaria, mencionaron la ayuda húngara notoria y consecuentemente en el último lugar al evaluar el apoyo de los países socialistas, dejando en claro su postura según la cual Hungría apoya a Nicaragua por debajo de sus posibilidades reales. ${ }^{37}$

La delegación húngara, desconcertada, mandó a casa un telegrama cifrado señalando que "se ha formado una imagen falsa en los líderes nicaragüenses sobre Hungría, y por eso no apreciaron debidamente nuestra ayuda". ${ }^{38}$

Tanto los ya mencionados problemas económicos en Hungría como el mal sabor de boca debido a la crítica a la asistencia húngara por parte del gobierno nicaragüense, más los cambios en la propia Unión Soviética bajo Gorbachov, podrían haber contribuido a un suceso bastante insólito. Cuando en octubre de 1988 la Unión Soviética pidió que Hungría suministrara 20000 toneladas de petróleo crudo a Nicaragua en 1989 y 1990 en forma de apoyo sin retribución, el gobierno húngaro dijo que no, alegando las condiciones preca-

\footnotetext{
35 MNL OL, KÜM, k, 1989, IV, Nicaragua, caja 89/111-1.

${ }^{36}$ Los datos de 1989 se refieren a los primeros diez meses del año.

37 MNL OL, KÜM, j, 1987, IV, Nicaragua, caja 102/111-503.1/005089/1.

38 MNL OL, KÜM, j, 1987, IV, Nicaragua, caja 102/111-503.1/005089/1.
} 
rias de su economía. Tras la reiteración del pedido, el Buro político tomó la decisión, el 13 de diciembre de 1988, de enviar 10000 toneladas de petróleo en 1989 y nuevamente en $19900^{39}$

La última visita de alto nivel entre Nicaragua y Hungría en la guerra fría tuvo lugar en marzo de 1989 en Budapest, con la llegada del comandante Carlos Núñez Téllez. El político afirmó que la solidaridad moral no era suficiente para ellos bajo las condiciones temporales tras la guerra, cuando no contaban con las herramientas necesarias para la reconstrucción. Necesitarían en total 250000000 de dólares para aliviar la crisis económica. Pidió que Hungría pusiera más voluntad en la cooperación, y que esta incluyera -también en el futuro- ayuda unilateral. El viceprimer ministro, doctor Péter Medgyessy, contestó que "no descartamos la ayuda unilateral sin retribución, pero le estamos asignando un papel decreciente" ${ }^{40} \mathrm{Al}$ respecto, dice mucho que el encuentro -que tuvo lugar el 14 de marzo-, no haya sido incluido en el anuario del Ministerio (Magyar Külpolitikai Évkönyv), ni en la prensa húngara. La visita del comandante posiblemente no se consideró de mucha importancia para la Hungría de 1989, cuando ya se sentían los vientos de cambio. El Partido Socialista Obrero Húngaro (MSZMP) había declarado en enero que en teoría estaba de acuerdo con el sistema pluripartidista, y el reconocido político Imre Pozsgay evaluó los eventos de 1956 como una sublevación del pueblo, en contraste con la versión oficial de que fue una contrarrevolución, concepto que se utilizó como una de las bases de la época Kádár. De hecho, János Kádár dejó de ser el secretario general del partido en mayo de 1988, convirtiéndose en su presidente -sin poder real-, cargo del cual fue relevado en mayo de 1989, junto con todas sus funciones restantes. Murió el 6 de julio de 1989. Una semana tras la visita de Núñez Téllez, a finales de marzo, se formó la mesa redonda nacional que agrupó a las fuerzas de la oposición, y sus representantes iniciaron las negociaciones con el MSZMP sobre las condiciones del cambio de sistema en el país.

El 10 de septiembre el gobierno húngaro tomó la decisión de abrir las fronteras occidentales y permitir el paso de los ciudadanos de la RDA -había unos 60000 en Hungría en aquel momento- quienes de esta manera pudie-

39 MNL OL, KÜM, k, 1989, IV, Nicaragua, caja 89/111-5. Posiblemente no se hizo en las circunstancias del cambio político y económico en Hungría. Aunque por un monto mucho más pequeño, valdría la pena mencionar la decisión 3189/1989 del Consejo Ministerial, hecha el 14 de julio de 1989 sobre el envío de un apoyo con valor de 3400000 de forintos.

${ }^{40}$ MNL OL, KÜM, k, 1989, IV, Nicaragua, caja 89/111-1. 
ron ir a Austria y eventualmente a la República Federal de Alemania. Esta medida contribuyó para el término del liderazgo de Eric Honecker en la RDA y para la caída del muro de Berlín. Sobre la reacción en Nicaragua, he aquí una opinión húngara:

Justificamos la reducción de nuestra política de asistencia a Nicaragua con la situación económica que enfrentamos. Al plantearles esto verbalmente [al parecer] lo entendieron, pero se puede percibir que deja su marca sobre la evaluación política de nuestros nexos. Por ejemplo, en cuanto a la ola de salida de los alemanes orientales, el diario central del FSLN publicó las declaraciones del embajador de la RDA en Managua, quien principalmente culpó a Alemania Occidental por lo ocurrido, pero también le reprochó a Hungría. ${ }^{41}$

Analizando el texto, se podría afirmar que la disminución del apoyo también impactó sobre las relaciones políticas.

En 1990 hubo elecciones tanto en Hungría como en Nicaragua. En el país centroamericano estas trajeron consigo el fin del gobierno sandinista y de la lucha armada, mientras en Hungría sellaron el final de la época socialista y el principio de la transición política, económica, social, etc. Desapareció el bloque socialista; pronto se enterró a la Unión Soviética; la guerra fría dejó de ser relevante, y con esto, la bipolaridad del mundo también. El cambio en las condiciones internacionales, así como en la situación interna de ambos países, destruyó el engranaje de la cooperación.

\section{CONCLUSIONES}

El principal obstáculo para una mayor cooperación en la década de 1980 fueron los intereses disparejos de Hungría y Nicaragua. Primero que nada, la parte nicaragüense esperó un comportamiento socialista de una Hungría socialista, incluyendo apoyo unilateral y comercio sin fines de lucro, esto es, una actitud solidaria. Hungría, en cambio, tomando como prioridad sus intereses nacionales, no quiso comportarse de una manera socialista en América Latina, sino más bien hacer negocio y obtener las muy necesarias divisas para comprar tecnología occidental y/o pagar parte de sus deudas. El gobierno sí

${ }^{41}$ MNL OL, KÜM, k, 1989, IV, Nicaragua, caja 89/111-1. 
envió auxilio a Nicaragua, pero tratando de buscar soluciones no costosas. Tendencias similares se pudieron observar en las relaciones checoslovaco-nicaragüenses y polaco-nicaragüenses, pero indudablemente la cantidad total de intercambio fue la más baja en el caso húngaro.

Aparece como queja, en la documentación húngara que se podía detectar, una falta de prioridades en los pedidos nicaragüenses. ${ }^{42}$ Esto tal vez se debía a los cambios drásticos que vivió aquel país, así como a la imagen exagerada que se tenía de las capacidades de Hungría: no había necesidad de priorizar si el país socio puede satisfacer todas las demandas. La realidad fue que Hungría ni pudo, ni quiso.

Las diferencias en los sistemas económicos complicaron también la intensificación de los nexos. Por ejemplo, la maquinaria, y en general la tecnología socialista, no necesariamente se podía aprovechar al máximo en un ambiente acostumbrado a tener este tipo de know-how de Estados Unidos y Japón (Edelman, 1985, p. 43). Los expertos socialistas enviados a petición del gobierno nicaragüense tenían experiencia de trabajo en entornos controlados por el estado, y no en economías mixtas, como era el caso de Nicaragua, lo cual impactó negativamente sobre su eficacia. Se puede añadir que las economías planificadas no fueron suficientemente flexibles para atender las demandas nicaragüenses, que iban cambiando de acuerdo con sus necesidades. Sin embargo, la otra cara de la moneda es que Hungría envió -a veces, no siempre- productos que le sobraban, estaban almacenados o incluso obstaculizaban la producción. ${ }^{43}$ Es decir, los envíos no necesariamente se hicieron conforme a las peticiones de Managua, sino tomando en cuenta 'la salud' de la economía húngara. Las discrepancias entre pedidos y envíos por tanto no fueron únicamente el resultado de la inflexibilidad de la economía planifica$\mathrm{da}$, sino de las decisiones de las propias autoridades húngaras, de ahorrar. El sector en Nicaragua que contaba con recursos y pudo haber hecho negocio con Hungría sobre bases capitalistas, era el sector privado, que sin embargo desconfiaba de los países socialistas.

La falta de antecedentes entre ambos países hizo el desarrollo de los vínculos más complicado (Edelman, 1985, p. 43). No había suficientes conocimientos del otro, ni experiencias de un entendimiento mutuo en el pasado. Aunque el liderazgo húngaro hubiera podido sentir más empatía con Nicara-

${ }^{42}$ MNL OL, KÜM, k, 1989, IV, Nicaragua, caja 89/111-1.

43 MNL OL, KÜM, k, 1983, IV, Nicaragua, caja 93/111-63. 
gua, por haber tenido fuertes lazos en el Caribe con Cuba, pasó lo opuesto, debido a los intereses económicos, ligados con el bienestar y la estabilidad interna de Hungría. Dentro del contexto de las relaciones intensivas entre Nicaragua y los Estados socialistas, el nexo húngaro-nicaragüense fue el menos fuerte -no contando a Rumania.

Por último, aunque no menos importante, hay que recalcar que la cooperación entre Hungría y Nicaragua abarcó áreas diversas, varias de las cuales no fueron analizadas en este escrito, principalmente debido a las limitaciones de espacio (contactos culturales, becas para estudiar en Hungría, construcción de una escuela técnica en Chinandega, auxilio en el caso de catástrofes naturales, tratamiento de enfermos nicaragüenses en Hungría, envío de entrenadores húngaros a Nicaragua, etc.). Aunque el presente trabajo no es por tanto comprehensivo, se pueden afirmar las hipótesis del principio: los objetivos soviéticos y húngaros coincidieron sólo parcialmente en Nicaragua. Por supuesto que la política exterior húngara se ajustó a las demandas soviéticas, pero solamente hasta el grado "necesario". El gobierno húngaro no fue un protector tenaz de los sandinistas; envió ayuda y promovió los lazos bilaterales, sí, pero trató de no incurrir en gastos, ya que consideró la estabilidad y el bienestar económico de Hungría como primordial. Esto, aunado a una imagen demasiado positiva de los países socialistas entre la izquierda latinoamericana, contribuyó a la formación de una diferencia abismal entre las expectativas nicaragüenses y el desempeño húngaro. Las fricciones resultantes -ocultas para la mayoría de los contemporáneos-colaboraron al rápido fin de la cooperación, una vez disueltas las presiones político-ideológicas.

El presente estudio pretende formar una base de comparación para investigaciones sobre las relaciones entre otros países socialistas y Nicaragua, así como también sobre los nexos entre Estados socialistas y países en vías de desarrollo. Este tipo de análisis podrían profundizar nuestros conocimientos sobre las políticas exteriores de los estados socialistas y las relaciones de solidaridad, así como también sobre las interacciones y normas en la guerra fría.

\section{LISTA DE REFERENCIAS}

Anderle, Á. (2007). A magyar forradalom és a hispán világ [La revolución húngara y el mundo hispano]. Szeged: Szegedi Tudományegyetem. 
Baráth, M. y Gecsényi, L. (eds.) (2015). Fókonzulok, követek és nagykövetek, 1945-1990 [Cónsules generales, enviados y embajadores, 1945-1990]. Budapest, MTA.

Békés, C. (2004). Hungarian foreign policy in the Soviet alliance system, 1968-1989. Foreign Policy Review, 3(1), 87-127.

Békés, C. (2011). Hungarian foreign policy in the bipolar world, 1945-1991. Foreign Policy Review, 8(1), 65-97.

Békés, C. (2012). Magyarország, a szovjet blokk és a nemzetközi politika az enyhülés idöszakában 1953-1991 [Hungría, el bloque socialista y la política internacional en el periodo de la Détente 1953-1991]. (Tesis de doctorado). Budapest, MTA.

Békés, C. (2014). Cold war, Détente and the Soviet bloc. The evolution of intra-bloc foreign policy coordination, 1953-1975. En M. Kramer y V. Smetana (eds.), Imposing, maintaining and tearing open the iron curtain: The cold war and east-central Europe, 1945-1989 (pp. 247-278). Lanham (MD), Estados Unidos: Lexington Books.

Berrios, R. (1985). Relations between Nicaragua and the socialist countries. Journal of Interamerican Studies and World Affairs, 27(3), 111-139. DoI: https://doi. org $/ 10.2307 / 165602$

Blank, S. (1993). Soviet foreign policy and conflict resolution in the third world: The Nicaraguan civil war. Journal of Conflict Studies, 13(4), 7-29.

Borhi, L. (2001). Empire by coercion. The Soviet Union and Hungary in the 1950s. Cold War History, 1(2), 43-72. DoI: https://doi.org/10.1080/713999917

Borhi, L. (2004a). Hungary in the cold war 1945-1956: Between the Soviet Union and the United States. Budapest-Nueva York: CEU Press.

Borhi, L. (2004b). János Kádár's foreign policy in the light of US-Hungarian relations. Foreign Policy Review, 3(1), 128-155.

Borhi, L. (2004c). "We Hungarian communists are realists": János Kádár's foreign policy in the light of Hungarian-US relations, 1957-67. Cold War History, 4(2), 1-32. DOI: https://doi.org/10.1080/14682740412331391795

Borhi, L. (2006). Hungary in the Soviet empire, 1945-1956, Hungarian Studies, 20(1), 21-30. DoI: https://doi.org/10.1556/HStud.20.2006.1.3

Borhi, L. (2010). Hadüzenettól rendszerváltásig: az Egyesült Államok és Magyarország, 1941-1991 [Desde la declaración de la guerra hasta el cambio de régimen: los Estados Unidos y Hungría, 1941-1991] (Tesis de doctorado). Budapest, MTA.

Bortlová Vondráková, H. (2011). Československo a Kuba v letech 1959-1962 [Checoslovaquia y Cuba en los años 1959-1962]. Praga: Universidad Carolina de Praga.

CIA (1986). Soviet policy toward Nicaragua. SOV-86-10061X. Recuperado de https:// www.cia.gov/library/readingroom/docs/DOC_0000499318.pdf 
Desjeans, M. y Clement, P. (1987). Soviet policy toward Central America. Proceedings of the Academy of Political Science, 36(4), 223-234. Dor: https://doi.org/10.2307/1173845

Edelman, M. (1985). Lifelines: Nicaragua and the socialist countries. NACLA Report on the Americas, 19(3), 33-56. Dor: http:/dx.doi.org/10.1080/10714839.1985.11723473

Evanson, R. K. (1986). Soviet economic and military trade in Latin America: An Assessment. World Affairs, 149(2), 75-85. Recuperado de www.jstor.org/ stable/20672092

Fischer, F. (2014). A kétpólusú világ, 1945-1989 [El mundo bipolar, 1945-1989]. Pécs: Dialóg Campus.

Fischer, F., Kozma, G. y Lilón, D. (2006). EncUEntros -Viejos y nuevos encuentros entre Hungría, Europa e Iberoamérica: 1956 y 2006. El Reflejo de la revolución húngara de 1956 en Iberoamérica. Pécs: Universidad de Pécs.

Horváth, E. (2018). A magyar-kubai diplomáciai kapcsolatok létrejöttének sajátos fordulatai [Giros particulares en el establecimiento de las relaciones diplomáticas entre Hungría y Cuba]. Aetas, 33(1), 50-68.

Kádár, B. (1988). A latin-amerikai országokkal folytatott együttműködésünk irányzatai, stratégiai összetevői, keretei és formái [Las tendencias, componentes estratégicos, marcos y formas de nuestra cooperación con los países de América Latina]. Külpolitika, 15(5), 98-112.

Kanet, R. E. (2006). The superpower quest for empire: The cold war and Soviet support for "Wars of National Liberation". Cold War History, 6(3), 331-352. DoI: https://doi.org/10.1080/14682740600795469

Kaplan, M. A. (1957). Balance of power, bipolarity and other models of international systems. The American Political Science Review, 51(3), 684-695. Recuperado de www. jstor.org/stable/1951855

Light, M. (1991). Soviet policy in the third world. International Affairs, 67(2), 263-280. DoI: https://doi.org/10.2307/2620830

Magyar Külpolitikai Évkönyv (1979). [Anuario de la Política Exterior Húngara]. Budapest: Külügyminisztérium.

Magyar Külpolitikai Évkönyv (1984). [Anuario de la Política Exterior Húngara]. Budapest: Külügyminisztérium.

Mujan-Leon, E. (1986). Soviet strategic perspectives on Latin America in the 1980s. World Affairs, 149(2), 101-106. Recuperado de www.jstor.org/stable/20672095

Romsics, I. (1999). Magyarország története a xx században [Historia de Hungría en el siglo xx]. Budapest: Osiris. 
Shearman, P. (1986). Soviet foreign in Africa and Latin America: A comparative case study. Millenium: Journal of International Studies, 15(3), 339-365. DoI: https://doi.or $\mathrm{g} / 10.1177 / 03058298860150030401$

Szente-Varga, M. (2005). El lugar de Cuba en el mundo político. Opiniones checoslovacas desde La Habana. En J. Opatrný (ed.), Nación y cultura nacional en el Caribe hispano (pp. 357-367). Praga: Universidad Carolina de Praga.

Szente-Varga, M. (2008). Relaciones políticas entre Cuba y Checoslovaquia en los años sesenta. En M. Chust e I. Frasquet (eds.), Actas XIV Congreso Internacional AHILA. Europa-América, paralelismos en la distancia (CD). Madrid: IHILA/Universitat Jaume I/Fundación Mapfre.

Szente-Varga, M. (2016). El proyecto urbanístico "La Habana”. ¿Un trozo de Cuba en Budapest? En J. Opatrný (ed.), Proyectos políticos y culturales en las realidades caribeñas de los siglos XIX y Xx. Praga: Editorial Karolinum.

Szente-Varga, M. (2018). Relaciones húngaro-nicaragüenses en la década de los 1980. En M. Alcántara, M. García Moreno y F. Sánchez López (eds.), Relaciones internacionales: 560 Congreso Internacional de Americanistas (pp. 78-86). Salamanca: Universidad de Salamanca.

Udvardi, P. (2015). Fidel Castro 1972-es magyarországi látogatása. Metszet a magyar-kubai kapcsolatok történetéből [La visita de Fidel Castro a Hungría en 1972. Un segmento de la historia de las relaciones húngaro-cubanas]. Múltunk, 60(4), 72-93.

Vanden, H. E. y Prevost, G. (1993). Democracy and socialism in sandinista Nicaragua. USA-UK: Lyne Rienner Publisher.

Zalai, A. (2010). A nemzetközi szocialista munkamegosztás egyik példája: kubai vendégmunkások Magyarországon [Un ejemplo de la división socialista internacional de labores: trabajadores cubanos en Hungría]. Mediterrán Világ, 16, 69-77.

\section{OTRAS FUENTES}

\section{Archivo}

MNL OL Magyar Nemzeti Levéltár, Országos Levéltára, Budapest, Hungary.

Külügyminisztérium (cÜM)

j (Titkos ügykezelésű iratok / documentos confidenciales)

1979, IV, Nicaragua, caja 102/111, 111-1

1980, IV, Nicaragua, caja 108/111-13, 108/111-65, 108/111-99 
1985, IV, Nicaragua, caja 113/111

1987, Iv, Nicaragua, caja 102/111

$\mathrm{k}$ (Adminisztratív iratok / documentos administrativos)

1981, IV, Nicaragua, caja 70/111-54

1982, IV, Nicaragua, caja 77/111-17

1983, IV, Nicaragua, caja 93/111-63

1984, IV, Nicaragua, caja 85/111-51

1988, IV, Nicaragua, caja 73/111-5

1989, IV, Nicaragua, caja 89/111-1, 111-5 